\title{
Discussion on the Goal-driven Teaching Method
}

\author{
Li Bo ${ }^{1, a^{*}}$, Cao Fuyi ${ }^{1}$, Lv Haihua ${ }^{1}$, Li Fengpeng ${ }^{1}$, Yu Shun ${ }^{1}$ \\ ${ }^{1}$ Shenyang Institute of Engineering, Shenyang, Liaoning,China, 110136 \\ albian@126.com
}

Key words: goal-driven; teaching mode reform; multi-level objectives and tasks system Abstract. Classroom teaching is an important part of higher education, the quality of education depends on the teaching effect. This paper is based on the demand analysis of enterprise, and points out that the problems which exist in the current teaching practice, then proposes "goal driven Teaching" mode to establish and implement this method, and put forward the multi-level objectives and tasks system which based on the 'goal driven' ideology, and to help students better their knowledge mastery. The method is applied to the teaching reform of the course of 'Android programming', with the aim of making it more suitable for developing students' practical skills. It has achieved good results judging from students' feedbacks.

Graduates from the IT industry are facing even greater difficulties in finding a decent job than those from other industries ${ }^{[1]}$, as the youth unemployment remains high across China. This is partially caused by an over-supply of IT graduates as IT courses are offered ubiquitously among Chinese universities ${ }^{[2]}$. What's more, IT study is also offered as a supplement curriculum in many other faculties, which has further reduced the room for the IT graduates in the job market. On the other hand, the skillset of those graduates is not matched by the demand of local employers who would struggle to recruit from time to time ${ }^{[3]}$. Meanwhile those graduates will have to fork out a fortune on top of the high tuition fee they had already paid, to get themselves retrained, in order to be attractive in the job market.

Therefore, the key to improve graduates' competitiveness in the employment market is to develop their practical computer engineering skills and combine the learning process with the special needs of local enterprises.

\section{Problems existed in the current teaching practice.}

In recent years, the domestic application oriented Undergraduate Colleges and universities have realized that enhancing the students' engineering practical skills is the key to improve the students' employment competitiveness ${ }^{[4]}$, and relevant reform is then carried out. For example, they try to introduce better teaching methodologies into theoretical lectures which otherwise would seem to be dreary and tedious ${ }^{[5]}$, increasing the amount of programming design for the application courses, and incorporate 'field tests' into students' appraisal system ${ }^{[6]}$.

These methods have a certain positive effect to enhance the students' engineering practice ability, but there are some insurmountable deficiencies. For example:

I The lack of clearly learning goal in the teaching process.

I There is a high degree of inconsistency between teaching content and the social demand.

I The lack of training in teamwork skills. 


\section{Structure of the goal-driven teaching mode}

According to the objective of national teaching reform the establishment of goal driven teaching mode is an improvement and supplement for the current teaching mode, it could adapt university graduates to the requirement of enterprise by improving the practical ability of students. It improves the communication between students and teachers in the whole teaching process, and enable the student to actively participate in the problem analysis and resolution process, turning passive learning into active learning. "Goal-driven" teaching method is proposed in this paper, based on the guideline of the course, which entails the extraction of knowledge and integrates all the useful content into a piece of software, named "goal work" and demonstrates to the students at the beginning of the course to make an overall impression. Then the course could be divided into several modules from the view of software development, then refined and taught to students, while checking their progress step by step. The initial results will have to be reproduced at the end of the process.

With the purpose of improving the students' practical ability, to research and practice the "goal-driven" teaching method in the course, we propose the goal-driven teaching mode operated in a flowing process which is "initial goal task — presentation — imitation learning — medium goal task-Intensive training —analysis and discussion-goal work show, evaluation and summary-advanced goal task". In the teaching process, teachers write on the blackboard and use multimedia to organize teaching based on the setting task, students can understand the basic theoretical knowledge through imitation learning, and intensive training, teachers can set up the medium goal task, initiate group discussion and interactive research delegate the freedom of problem solving to students, students can research after class. In the process of goal driven teaching mode, teacher as the main body in the initial phase and the students as the main body in the following phase, it will reduce the amount of teaching by teachers and increase the amount of analysis and discussion, as well as the opportunity for student participate actively, thereby we can arouse the interest of study by communication and cooperation between students and teachers, to achieve better teaching and learning outcome.

\section{The Design of goal driven educational system}

\section{Layered design of mission target}

The key to the objective driven teaching system lies in the establishment of mission target, which comes in three phases: the primary objective, the intermediary objective, and the advanced objective. The layers of mission targets are designed on the basis of progresses made by each individal student, who can at least achieve the lowest acceptable learning outcome by accomplishing the requirement of the primary objectives. Students can conduct group work and discussion after having learned the textbook knowledge, in order to achieve intermediary objective. Thereby the element of rote learning is reduced and students can now take their own initiatives to analyze problems and find solutions. Their work can be evaluated and presented to others who might want to learn from it. The most valuable thing is that students can develop their team working spirit, increase their understanding of the textbook knowledge in a real world context, as well as gaining practical skills they may find useful in the future workplace.

Finally, for those who can perform extraordinarily well academically, greater future opportunities can be available to them, given that they can fulfill what is required from them by the advanced mission standard. 


\section{Develop team-working skills while practicing on computers}

Students are expected to have better understanding of theoretical knowledge they have learned in classroom while practicing on computers, in accordance with the learning objectives set out by target mission. There is also another vitally important aspect of learning our new teaching system must change. That is to develop their team working skills and practical applicative skills. Students used to focus on their own task with little regard to what other students are doing. Some of them are highly unmotivated and would simply copy other people's work. What we are going to do under the new teaching system here, is to divide our students into teams and appoint a team leader for each team, who is responsible to allocate tasks among team members and tracking team progress. Meanwhile, we evaluate the performance in the unit of a team, rather than its individual team members. This will nudge the students towards taking their own initiatives to work together, support each other and communicate effectively.

\section{Implementation of the goal-driven teaching mode}

\section{Android employment market demand analysis}

In recent years, due with the rapid spread of smart phones, smart, the relevant business has also been explosive development based on smart phones. Thus, the demand in the short term will be in short supply, the software development technology under the Android system will be a hot spot for years in the future. In the long run, with the increasing demand for various mobile applications and mobile games and other content will inspire large and small mobile application developers to increase the Android application development efforts, so it is extensive prospect of Android talent employment.

\section{classroom implementation}

To verify that the teaching effect of goal driven teaching mode, this paper based on the Android programming course as an example, and do the teaching reform by select the a number of 25 student class in computer major for practice.

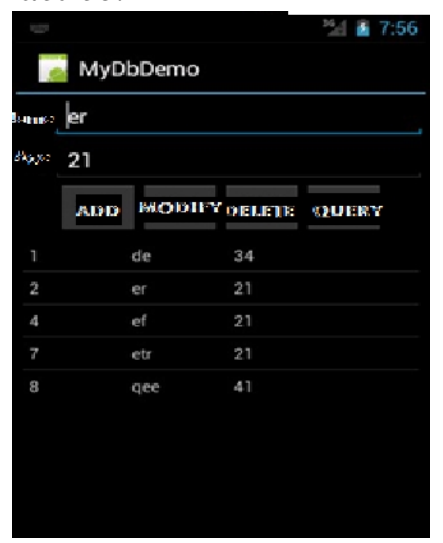

Figure 1 the GUI of data management

In order to realize the user information management function of a system as an example, the effect of operation as shown in Figure 1, the management personnel can be through click record were selected, and the user information of add, delete and save operation.

The function of information management is divided into two main parts, namely data operation and GUI display interface as shown in Figure 2. Data operation is mainly referred to the operation of data persistence, specifically related to the operation of the SQLite database, including database creation and deletion, data additions, deletion, modify and query function,. GUI interface including the layout of the interface, user response, data display light several parts of the content. The 
Android system though the listview component to the user display data and the user interactive response, involving a list display style, filled with data and user interaction function.

In the thinking of goal driven teaching mode, first of all, demonstration the figure 2 goal work to the students, so that students understand the specific purpose of the knowledge learned. Then, the goal work is divided into various functions, and then the knowledge points are extracted and the related knowledge points are divided into three categories, such as, Initial goal task, medium goal task and advanced goal task. Finally, the teacher carries on the goal teaching according to the goal of the task, and the students can form the goal after completing all the learning goals, and can carry out further innovation.

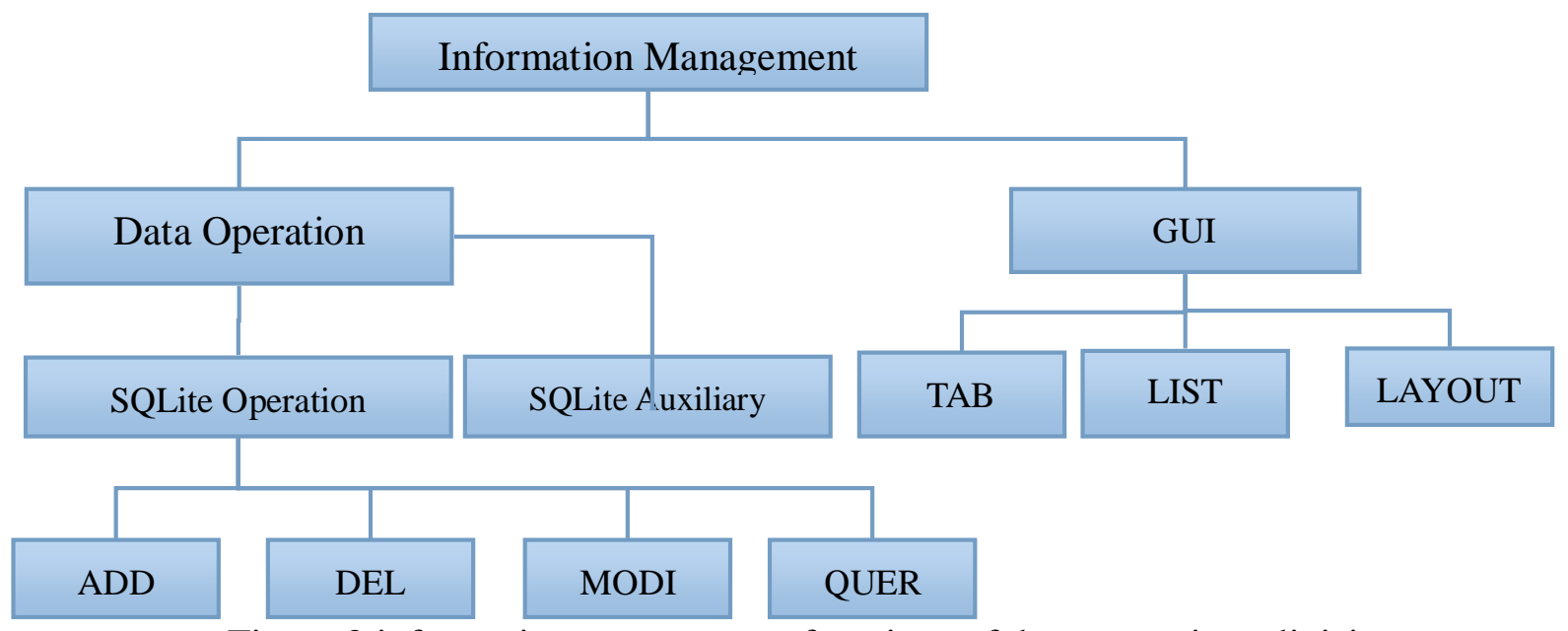

Figure 2 information management functions of data operations division

According to the function partition, the user information management function can form the overall goal, the initial goal, the medium goal, the advanced goal and multi - level task as shown in table 1.

Table 1 "user information management function" goal task design

\begin{tabular}{|c|c|c|}
\hline \multicolumn{3}{|c|}{ Overall objective } \\
\hline \multicolumn{3}{|c|}{$\begin{array}{l}1 \text { to achieve user information management functions } \\
2 \text { handle the use of ListView controls } \\
3 \text { handle Android response to the user's request } \\
4 \text { to understand the access mode of SQLite database and the operation of database. }\end{array}$} \\
\hline \multicolumn{3}{|c|}{ Initial goal task } \\
\hline Objective & Content & Method \\
\hline Creation of GUI and database & $\begin{array}{c}\text { Creation of layout } \\
\text { Addition and deletion of } \\
\text { database }\end{array}$ & $\begin{array}{l}\text { (1) teacher demonstrates the } \\
\text { method of how to establish } \\
\text { and delete the database. } \\
\text { (2) student repetition operation } \\
\text { of teacher. }\end{array}$ \\
\hline \multicolumn{3}{|c|}{ Medium goal task } \\
\hline Objective & Content & Method \\
\hline Data operation & $\begin{array}{l}\text { Data filling of ListView } \\
\text { Addition, deletion, } \\
\text { modification, and query of } \\
\text { SQLite database }\end{array}$ & $\begin{array}{l}\text { (1) teacher demonstrates the } \\
\text { method of control and data } \\
\text { operation. } \\
\text { (2) student repetition operation } \\
\text { of teacher. }\end{array}$ \\
\hline \multicolumn{3}{|c|}{ Advanced goal task } \\
\hline Objective & Content & Method \\
\hline $\begin{array}{l}\text { Design method for advanced } \\
\text { programming }\end{array}$ & $\begin{array}{l}\text { The database operations are } \\
\text { encapsulated into the database } \\
\text { operation class, and the } \\
\text { database is operated by the } \\
\text { database operation class. }\end{array}$ & $\begin{array}{l}\text { (1) teacher explain the method } \\
\text { and the significance of the } \\
\text { establishment of auxiliary } \\
\text { class. } \\
\text { (2) student repetition operation } \\
\text { of teacher. }\end{array}$ \\
\hline
\end{tabular}


Teachers according to the goal task list teach students step by step, to ensure that the general students were able to complete the initial goal task and medium goal tasks, ensure excellent students can perform advanced goal tasks, and the students were scored quantitatively, inspire learning enthusiasm of the students.

\section{Effect Evaluation of goal-driven teaching mode}

Overall, in practice processing of goal driven teaching mode, the students with the high participate enthusiasm to find a way to solve the problem in the discussion and communication between students and teacher.

Through the implementation of the goal-driven teaching mode in the "Android programming" course, we summed up a lot of experience and lessons. In the end of the course, the students were surveyed with an anonymous questionnaire and the results were statistically investigated.

By the result of the survey visible, $95 \%$ of the students accepted goal driven teaching method reform; more than $90 \%$ of the students are satisfied for the teaching reform of the learning habits; $40 \%$ of the students think goal driven teaching methods so that they get better learning effect, at the same time, nearly $60 \%$ of the learning task is currently driven teaching methods and the traditional teacher Professor effect is similar; $90 \%$ of the students said want to join next time goal driven teaching methods reform.

\section{Conclusion}

All in all, this paper puts forward the teaching mode of goal-driven through the practice of classroom teaching, and got the students' recognition. Multi - level task system for students' mastery of knowledge has a certain role in promoting, goal driven methods to enable students to understand their own knowledge of the application of, and be able to innovate on the classroom application based on. Although there are some difficulties in the practice of this subject, but in the joint efforts of teachers and students, the teaching effect is achieved. Practice shows that the teaching mode of goal-driven has the value of further promotion.

\section{References}

[1] Liang Jm. Zhang Jg. Xv Yy, The research to the influential factors of university students' employment competitive power, Journal of central south forestry university of science and technology, 2011 (03).

[2] Hong Y. Wu Jh. University students' employment competitiveness empirical research and thinking, Population \& Economics,2011(02)

[3] Li Zw. Fu J. Qiu Y, The empirical study of factors affecting college students' employment competitiveness, journal of zhejiang university of technology,2010(01)

[4] Gao Zl. The reason for difficulties in employment "anttribe" group and countermeasure research, Studies in Ideological Education,2014(1)

[5] Zhang $\mathrm{Hb} . \mathrm{Wu} \mathrm{H}$. Goal driven research and practice experience type teaching mode, The contemporary education theory and practice,2011(8)

[6] He L. Cai Yc. Goal driven method in the teaching of computer software technology based practice, The contemporary education theory and practice, 2010(6) 